\title{
Biochemical Mechanisms of Red Blood Cell 2,3-Diphosphoglycerate Increase at High Altitude
}

\author{
LORNA GRINDLAY MOORE ${ }^{1}$ AND GEORGE J. BREWER ${ }^{2}$ \\ Departments of Human Genetics and Anthropology, University of Michigan, \\ Ann Arbor, Michigan 48104
}

\author{
KEY WORDS High altitude, 2,3-DPG, enzyme \\ activation, glycolysis
}

\begin{abstract}
Red blood cell 2,3 diphosphoglycerate (2,3-DPG) levels increase after ascent to high altitude. Studies were undertaken to identify the biochemical mechanisms responsible for eliciting the 2,3-DPG response in several types of subjects. These included (1) short-term exposure to $3400 \mathrm{~m}$ in ten subjects; (2) exposure to $4300 \mathrm{~m}$ in an additional ten subjects; (3) studies in 28 high-altitude normal residents of $3100 \mathrm{~m}$; and (4) studies in 28 high-altitude residents with chronic mountain polycythemia. Controls were 41 residents of $240 \mathrm{~m}$. Regression analysis identified the glycolytic variables, termed "key variables," on which variation in $2,3-\mathrm{DPG}$ levels was dependent $(\mathrm{P}<.05)$. Key variables common to the short-term studies were glucose-6-phosphate, phosphoenolpyruvate, and the ratio of the levels of adenosine diphosphate to adenosine triphosphate. The positions of these key variables in the glycolytic pathway and their mean levels suggest erythrocyte hexokinase and pyruvate kinase activation as possible enzymatic mechanisms. Key variables unique to the $3400 \mathrm{~m}$ study suggested phosphofructokinase activation also acted to increase 2,3-DPG levels. 2,3-DPG levels in the normal $3100 \mathrm{~m}$ residents were not different from low-altitude values, and 2,3-DPG levels in these samples did not appear to be dependent on any of the glycolytic variables examined. Among the high-altitude residents with polycythemia, higher 2,3-DPG levels were dependent on glucose-6-phosphate, fructose diphosphate, dihydroxyacetone phosphate, and the ratio of adenosine diphosphate to adenosine triphosphate levels. The positions of these variables in the glycolytic pathway and their mean levels suggested activation of the hexokinase and phosphofructokinase enzymes.
\end{abstract}

Components of the oxygen transport system respond to high altitude in ways which help compensate for the reduced partial pressure of oxygen. The red blood cell responds metabolically with a build-up of 2,3-diphosphoglycerate (2,3-DPG) levels (Lenfant et al., '68; Eaton et al., '69). Increased 2,3-DPG levels decrease hemoglobin-oxygen affinity, or shift the oxygen dissociation curve rightward, which can be expected to augment tissue oxygen delivery if arterial oxygen saturation remains high.

Our purpose was to identify the biochemical mechanisms that were most likely responsible for the previously reported increase in 2,3-DPG levels. Studies were conducted (1) under baseline conditions and during short-term (8-10 days) high-altitude exposure to $3400 \mathrm{~m}$ at
Climax, Colorado, and to $4300 \mathrm{~m}$ on Pike's Peak, Colorado; (2) among normal residents of Leadville, Colorado $(3100 \mathrm{~m})$; (3) among residents of Leadville with chronic mountain polycythemia; and (4) for comparative purposes, among residents of Ann Arbor, Michigan $(240 \mathrm{~m})$. Possible biochemical mechanisms were defined by first identifying the glycolytic intermediates on which the variation in 2,3DPG levels was statistically dependent. The positions of these intermediates in the glyco-

\footnotetext{
${ }^{1}$ Current address: Anthropology Department, University of Colorado at Denver, 1100 Fourteenth Street, Denver; Colorado 80202.

${ }^{2}$ Reprint requests: Dr. George J. Brewer, Department of Human Genetics, University of Michigan Medical Center, 1137 East Catherine Street. Ann Arbor, Michigan 48104

Received September 4, 1979; accepted January 23, 1980
} 
lytic pathway and the changes in their mean levels after high-altitude exposure were inspected. Inferences were then drawn concerning the enzymatic mechanisms most likely responsible for elevating 2,3-DPG levels. These inferences are based both upon the data of this paper and the prior knowledge of the rate-limiting enzymes in human red cell glycolysis.

An understanding of the mechanisms responsible for 2,3-DPG control is critical for understanding the red blood cell metabolic response to high altitude and for the ultimate goal of understanding genetic adaptation of the red blood cell to high altitude. The present studies advance this goal insofar as the examination of the red blood cell metabolic response permits the analysis of the effects of high altitude to move closer to the level of gene action. Knowledge about 2,3-DPG control is also important for understanding red blood cell response to the hypoxic stresses of cardiovascular, pulmonary and hematological disorders.

\section{MATERIALS AND METHODS}

\section{Study groups}

Short-term studies (Climax and Pike's Peak)

Five male and five female adult Caucasian laboratory personnel from Ann Arbor, Michigan $(240 \mathrm{~m})$, were brought to the $3400 \mathrm{~m}$ elevation of Climax, Colorado, and remained there for eight days. Male-female mean sex differences in this sample (and the Pike's Peak study) were removed by simple linear regression. Blood samples were drawn before ascent in Ann Arbor and after six hours, two days, four days, six days, and eight days in Climax. Informed consent was obtained from these and the other subjects in the short- and long-term studies.

Seven U.S. Army enlisted men and three female laboratory personnel were housed on top of Pike's Peak, elevation $4300 \mathrm{~m}$, for ten days. All subjects were Caucasian residents of Denver, Colorado (1600 m) except one who had come from a lower altitude $(240 \mathrm{~m})$. Blood samples were drawn before ascent in Denver and then after six hours, two days, four days, seven days, and ten days on Pike's Peak.

Long-term studies (Leadville and Ann Arbor)

Normal high-altitude residents consisted of 28 Caucasian males who had lived in Leadville, Colorado $(3100 \mathrm{~m})$, for more than one year. None reported having any difficulty in adjusting to Leadville's altitude, and all had hematocrits of less than 55 volumes percent.

Twenty-eight males, also Caucasian residents of Leadville, Colorado $(3100 \mathrm{~m})$, for at least one year, with chronic mountain polycy- themia were chosen from the records of the St. Vincent's Hospital in Leadville. These subjects were identified on the basis of having hematocrits consistently above 55 volumes percent in the absence of phlebotomy.

Forty-one healthy male Caucasian residents of Ann Arbor, Michigan (240 m), made up the low-altitude sample. All had lived in Ann Arbor for at least one year.

Study variables. Blood $(20 \mathrm{ml})$ from the antecubital vein was drawn to measure hematocrit using the capillary tube method. Well-mixed samples $(0.5 \mathrm{ml})$ were immediately precipitated in trichloroacetic acid, frozen in dry ice and transported to Ann Arbor for determination of 2,3-diphosphoglycerate and adenosine triphosphate levels enzymatically (Kornberg, '50; Brewer and Powell, '66; Keitt, '71). Additional well-mixed samples $(10 \mathrm{ml})$ were precipitated immediately in perchloric acid, frozen in dry ice and transported to Ann Arbor for measuring glucose-6-phosphate, fructose6-phosphate, fructose diphosphate, dihydroxyacetone phosphate, 3-phosphoglycerate, 2phosphoglycerate, phosphoenolpyruvate, pyruvate, lactate, and adenosine diphosphate using enzymatic methods of Minakami et al. ('65) as modified by Oelshlegel et al. ('72). Hemoglobin was read colorimetrically from well-mixed hemolysates that had been frozen and transported to Ann Arbor.

Statistics. Regression analysis was used to assess the relationship between variation in 2,3-DPG levels and the variation in each of the other glycolytic intermediates or cofactors. The coefficient of determination $\left(\mathbf{r}^{2}\right)$ was computed for each variable in each study group and, in the short-term studies, at each measurement time. Computations were performed for the glycolytic variables when expressed both in $\mu \mathrm{moles} / \mathrm{gm} \mathrm{Hb}$ and in $\mu$ moles/liter red blood cell water. Variables whose $r^{2}$ values were significant $(P<.05)$ for both units of measurement were termed "key variables" insofar as it is variation in these variables that is most closely linked (statistically) to variation in 2,3-DPG levels.

In the short-term studies, change in the mean levels of the variables over all the measurement times was determined with the Hotelling $\mathrm{T}^{2}$ test. Comparison of variable means in the Ann Arbor normal with the Leadville normal and Leadville polycythemic samples was made using the two-sample (Student's) t-test. The Scheffe correction for multiple comparisons was used to avoid the inflation of type I errors incurred by multiple use of the t-test. 
Mean differences are reported as significant when $\mathbf{P}<.05$. Values are reported as mean \pm SEM.

\section{RESULTS}

\section{Short-term studies (Climax and Pike's Peak)}

2,3-DPG levels increased during short-term exposure at Climax (3400 m) and Pike's Peak $(4300 \mathrm{~m})$ (Fig. 1, Tables 1 and 2). Maximal increases of $15-20 \%$ above baseline values occurred at both altitudes. The rise in 2,3-DPG levels at Pike's Peak was more rapid than at Climax, where a transient decrease initially occurred.

Key variables identified in the Climax study were glucose-6-phosphate, fructose diphosphate, dihydroxyacetone phosphate, 2-phosphoglycerate, phosphoenolpyruvate, and the ratio of adenosine diphosphate to adenosine triphosphate (Fig, 2). At Pike's Peak, the key variables were glucose-6-phosphate, 3-phosphoglycerate, phosphoenolpyruvate, and the ratio of adenosine diphosphate to adenosine triphosphate levels (Fig. 2). Inspecting their positions in the glycolytic pathway reveals that, among the key variables common to both studies, adenosine diphosphate/adenosine triphosphate is involved at the four kinase steps, glucose-6-phosphate is the product of the hexokinase step and the substrate for phosphoglucose isomerase, and phosphoenolpyruvate is the pyruvate kinase substrate and the enolase product (Fig. 2). Additional key variables at Climax (fructose diphosphate, dihydroxyacetone phosphate, 2-phosphoglycerate) participate in the phosphofructokinase, aldolase, triose phosphate isomerase, phosphoglucomutase and enolase steps. At Pike's Peak, the additional key variable (3-phosphoglycerate) is the product of the diphosphoglycerate phosphatase step and the substrate for the phosphoglucomutase step (Fig. 2).

Among the key variables, the ratio of adenosine diphosphate to adenosine triphosphate decreased at Pike's Peak, glucose-6phosphate levels increased in both studies, and phosphoenolpyruvate levels changed during both short-term studies. Additional glycolytic variables changing in both studies were fruc-

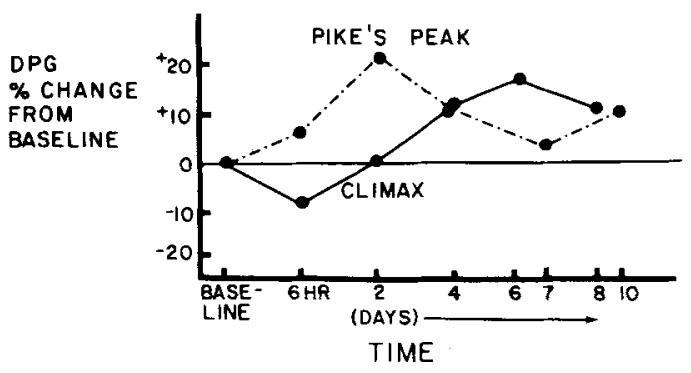

Fig. 1. Time course of changes in mean 2,3-DPG levels. Samples sizes $=10$ for Pike's Peak $(4300 \mathrm{~m})$ and Climax $(3400 \mathrm{~m})$ at each measurement time.

TABLE 1. Glycolytic and hematologic variables during climax $(3400 \mathrm{~m})$ study $(n=10)$

\begin{tabular}{|c|c|c|c|c|c|c|c|}
\hline Variable & $\begin{array}{c}\text { Ann Arbor } \\
\text { baseline }\end{array}$ & 6 Hours & 2 Days & 4 Days & 6 Days & 8 Days & $T^{2}$ test \\
\hline 2,3-DPG' & 8452 & 8193 & 8830 & 9777 & 10087 & 9436 & $\mathrm{P}<.05$ \\
\hline ADP/ATP ratio, units & .112 & .132 & .111 & .133 & .112 & .113 & \\
\hline Glucose-6-phosphate & 45 & 50 & 55 & 52 & 56 & 54 & $\mathrm{P}<.05$ \\
\hline Fructose-6-phosphate & 14 & 15 & 14 & 13 & 14 & 15 & \\
\hline Fructose diphosphate & 2.5 & 3.2 & 2.2 & 2.9 & 1.7 & 1.4 & $\mathrm{P}<.05$ \\
\hline \multicolumn{8}{|l|}{ Dihydroxyacetone } \\
\hline phosphate & 15 & 17 & 11 & 12 & 13 & 14 & \\
\hline 3-Phosphoglycerate & 111 & 115 & 105 & 103 & 99 & 88 & $\mathrm{P}<.05$ \\
\hline 2-Phosphoglycerate & 11 & 15 & 11 & 13 & 13 & 12 & \\
\hline Phosphoenolpyruvate & 21 & 22 & 19 & 23 & 23 & 18 & $P<.05$ \\
\hline Pyruvate $\mu$ moles/liter W.B. & 48 & 40 & 78 & 41 & 42 & 46 & \\
\hline Lactate $\mu$ moles/liter W.B. & 894 & 1084 & 993 & 781 & 680 & 939 & $\mathrm{P}<.05$ \\
\hline Hemoglobin $\mathrm{g} / 100 \mathrm{ml}$ W.B. & 14.8 & 14.9 & 15.1 & 14.8 & 15.1 & 15.8 & $\mathrm{P}<.05$ \\
\hline
\end{tabular}

${ }^{1}$ Variables are expressed in $\mu$ moles/liter RBC water except as indicated otherwise. W.B. $=$ whole blood. 
TABLE 2. Glycolytic and hematologic variables during Pike's Peak $(4300 \mathrm{~m})$ study $(n=10)$

\begin{tabular}{|c|c|c|c|c|c|c|c|}
\hline Variable & $\begin{array}{l}\text { Denver } \\
\text { baseline }\end{array}$ & 6 Hours & 2 Days & 4 Days & 7 Days & 10 Days & $\mathrm{T}^{2}$ test \\
\hline $2,3 \mathrm{DPG}^{1}$ & 7830 & 8304 & 9413 & 8839 & 8013 & 8326 & $\mathrm{P}<.05$ \\
\hline ADP/ATP ratio, units & .179 & .132 & .154 & .147 & .201 & .164 & $P<.05$ \\
\hline Glucose-6-phosphate & 58 & 55 & 60 & 64 & 60 & 64 & $\mathrm{P}<.05$ \\
\hline Fructose-6-phosphate & 14 & 11 & 12 & 12 & 13 & 12 & \\
\hline Fructose diphosphate & 2.0 & $3.2^{-2}$ & 4.3 & 4.0 & 4.7 & 4.6 & $\mathrm{P}<.05$ \\
\hline \multicolumn{8}{|l|}{ Dihydroxyacetone } \\
\hline phosphate & 15 & 17 & 20 & 16 & 21 & 17 & \\
\hline 3-Phosphoglycerate & 81 & 89 & 98 & 88 & 94 & 93 & $\mathbf{P}<.05$ \\
\hline 2-Phosphoglycerate & 33 & 14 & 10 & 15 & 13 & 12 & \\
\hline Phosphoenolpyruvate & 27 & 25 & 27 & 20 & 29 & 20 & $\mathbf{P}<.05$ \\
\hline Pyruvate $\mu$ moles/liter W.B. & 56 & 58 & 53 & 58 & 47 & 63 & \\
\hline Lactate $\mu$ moles/liter W.B. & 855 & 1149 & 944 & 1404 & 930 & 1408 & \\
\hline Hemoglobin g/100 ml W.B. & 16.0 & 16.3 & 15.9 & 16.6 & 16.2 & 17.4 & $\mathbf{P}<.05$ \\
\hline
\end{tabular}

${ }_{1}$ Variables are expressed in $\mu$ moles/liter RBC water unless indicated otherwise. W.B. $=$ whole blood.

tose diphosphate and 3-phosphoglycerate. Lactate levels increased during the Climax study (Tables 1 and 2).

\section{Long-term studies (Leadville and Ann Arbor)}

2,3-DPG levels among Leadville residents with chronic mountain polycythemia were higher than those of Ann Arbor residents. The 2,3-DPG levels of Leadville normals also tended to be higher, but differences with Ann Arbor values were not statistically significant (Table 3).

Key variables could not be identified in either the Ann Arbor normal or Leadville normal samples due to the absence of significant relationships between 2,3-DPG and other glycolytic variables. In the Leadville polycythemic sample, key variables were glucose-6. phosphate, fructose-6-phosphate, dihydroxyacetone phosphate, and the ratio of adenosine diphosphate to adenosine triphosphate levels. These variables are found principally in the early enzymatic steps of glycolysis (Fig. 3) where glucose-6-phosphate is produced at the hexokinase step, fructose-6-phosphate is the substrate and fructose diphosphate is the product of the phosphofructokinase step, dihydroxyacetone phosphate is the product of the aldolase step and the substrate for triose phosphate isomerase, and the adenosine diphosphate/adenosine triphosphate ratio is a cofactor for each of the kinase steps (Fig. 3).

Dihydroxyacetone phosphate, 3-phosphoglycerate, and lactate levels were elevated in the Leadville polycythemic subjects, and phosphoenolpyruvate values were lower compared to the Ann Arbor sample. Among these, only dihydroxyacetone phosphate was a key vari- able. 3-Phosphoglycerate and phosphoenolpyruvate were also variables undergoing change in the Leadville normal subjects (Table 3).

\section{DISCUSSION}

Erythrocyte 2,3-DPG levels increased during short-term exposure to $3400 \mathrm{~m}$ and to $4300 \mathrm{~m}$ and after long-term exposure in subjects with chronic mountain polycythemia. Hypoxia would appear to be the primary stimulus, but the mechanisms by which hypoxia stimulates an increase in red blood cell 2,3-DPG levels are not clear. One mechanism is probably alkalosis, induced by hyperventilation, which in turn stimulates in vivo phosphofructokinase activity. However, this mechanism is not solely responsible for elevating 2,3-DPG levels since 2,3-DPG levels are known to increase in the absence of $\mathrm{pH}$ changes (Cymerman et al., '76) and patterns of change in the levels of glycolytic intermediates have been observed during hypoxia that are consistent with the activation of other enzymes (Moore et al., '72).

The present study identified "key variables," defined as those glycolytic intermediates on which variation in 2,3-DPG levels was depen$\operatorname{dent}\left(r^{2}, p<.05\right)$. The positions of these variables in the glycolytic pathway pointed to enzyme steps potentially involved in 2,3-DPG regulation during short-term high-altitude exposure (Fig. 2) and among Leadville residents with chronic mountain polycythemia (Fig. 3). Since each key variable involves a minimum of two enzymes (the enzyme producing and the enzyme catabolizing the intermediate), the task remains to determine for each study which enzymes were most likely involved in 2,3-DPG regulation. 


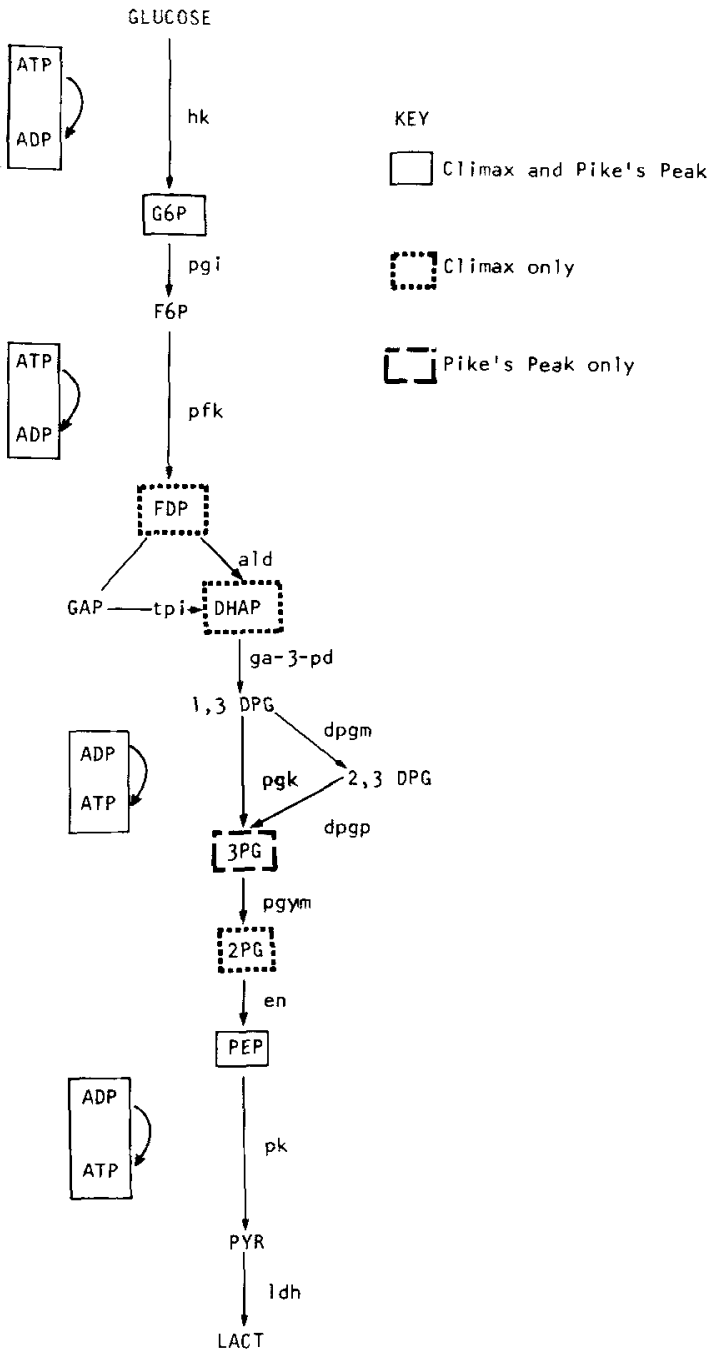

Fig. 2. Key variables (in boxes) in short-term studies.

ATP, adenosine triphosphate ADP, adenosine diphosphate $\mathrm{hk}$, hexokinase G6P, glucose-6-phosphate pgi, phosphohexose isomerase F6P, fructose-6-phosphate pfk, 6-phosphofructokinase FDP, fructose 1,6-diphosphate ald, adolase GAP, glyceraldehyde 3-phosphate tpi, triosephosphate isomerase DHAP, dihydroxyacetone phosphate ga-3-pd, glyceraldehyde-3-phosphate dehydrogenase dpgm, diphosphoglycerate mutase
1,3 DPG, 1,3-diphosphoglycerate 2,3 DPG, 2,3 diphosphoglycerate pgk, 3-phosphoglycerate kinase dpgp, 2,3-diphosphoglycerate phosphatase 3PG, 3 phosphoglycerate pgym, 2,3-phosphoglycerate mutase 2PG, 2 phosphoglycerate en, enolase

PEP, phosphoenolpyruvate pk, pyruvate kinase

PYR, pyruvate

ldh, lactate dehydrogenase

LACT, lactate 
TABLE 3. Variables measured in groups of high $(3100 \mathrm{~m})$ low $(240 \mathrm{~m})$ altitude residents

\begin{tabular}{|c|c|c|c|c|c|}
\hline \multirow[b]{2}{*}{ Variable } & \multirow{2}{*}{$\begin{array}{c}(1) \\
\text { Leadville } \\
\text { polycythemics }\end{array}$} & \multirow{2}{*}{$\begin{array}{c}\text { (2) } \\
\text { Leadville } \\
\text { normals }\end{array}$} & \multirow{2}{*}{$\begin{array}{c}\text { (3) } \\
\text { Ann Arbor } \\
\text { normals }\end{array}$} & \multicolumn{2}{|c|}{ t-test } \\
\hline & & & & (1) vs (3) & (2) vs (3) \\
\hline 2,3-DPG ${ }^{1}$ & $8823 \pm 225$ & $8535 \pm 142$ & $8167 \pm 122$ & $\mathbf{P}<.05$ & \\
\hline ADP/ATP ratio (units) & .110 & .127 & .120 & & \\
\hline Glucose-6-phosphate & $58 \pm 3$ & $55 \pm 2$ & $53 \pm 2$ & & \\
\hline Fructose-6-phosphate & $17 \pm 1$ & $15 \pm 1$ & $12 \pm 2$ & & \\
\hline Fructose diphosphate & $3.0 \pm .5$ & $1.8 \pm .2$ & $2.5 \pm .3$ & & \\
\hline Dihydroxyacetone & & & & & \\
\hline phosphate & $22 \pm 2$ & $14 \pm 2$ & $12 \pm 1$ & $P<.05$ & \\
\hline 3-Phosphoglycerate & $100 \pm 5$ & $104 \pm 4$ & $77 \pm 6$ & $\mathrm{P}<.05$ & $\mathrm{P}<.05$ \\
\hline 2-Phosphoglycerate & $12 \pm 1$ & $12 \pm 1$ & $11 \pm 2$ & & \\
\hline Phosphoenolpyruvate & $18 \pm 1$ & $19 \pm 1$ & $23 \pm 1$ & $\mathrm{P}<.05$ & $\mathbf{P}<.05$ \\
\hline $\begin{array}{l}\text { Pyruvate, } \\
\mu \text { moles/liter W.B. }\end{array}$ & $50 \pm 5$ & $42 \pm 4$ & $46 \pm 4$ & & \\
\hline $\begin{array}{l}\text { Lactate, } \\
\mu \text { moles/liter W.B. }\end{array}$ & $1284 \pm 153$ & $888 \pm 52$ & $729 \pm 72$ & $\mathrm{P}<.05$ & \\
\hline $\begin{array}{l}\text { Hemoglobin, } \\
\text { g/100 ml W.B. }\end{array}$ & $19.0 \pm .4$ & $17.3 \pm .2$ & $15.8 \pm 0.2$ & $\mathrm{P}<.05$ & $P<.05$ \\
\hline
\end{tabular}

Variables are expressed in $\mu$ moles/liter RBC water except as indicated otherwise. W.B. = whole blood.

In both the short-term studies, glucose-6phosphate, phosphoenolpyruvate, and the ratio of adenosine diphosphate to adenosine triphosphate were identified as key variables. Four other variables were determined to be key variables in one or the other of the two studies (Fig. 2). Distinguishing the ratio of adenosine diphosphate to adenosine triphosphate as a key variable is not very specific, since those cofactors are involved in all of the four kinase steps of the glycolytic pathway. However, the determination of glucose-6-phosphate and phosphoenolpyruvate as key variables in both studies suggests important roles for two of the kinases, hexokinase and pyruvate kinase, in the modulation of glycolysis at high altitude. Since both hexokinase and pyruvate kinase are rate-limiting steps in glycolysis (Minakami and Yoshikawa, '66), glucose-6-phosphate and phosphoenolpyruvate levels are more likely a reflection of their activities than of the nonrate-limiting enzymes, phosphoglucose isomerase and enolase. In the Climax study, the identification of fructose diphosphate and dihydroxyacetone phosphate suggest that a third kinase and the third rate-limiting enzyme, phosphofructokinase, is also involved in 2,3DPG regulation.

The absence of key variables in the Leadville normal residents and similarity in intermediate levels with Ann Arbor residents suggests the completion of acclimatization in the Leadville group renders them no longer hypoxic. If so, hypoxia must be present in order to identify key variables on which 2,3-DPG levels are dependent.
The key variables identified in the Leadville residents with chronic mountain polycythemia parallel to a certain extent those of the shortterm studies (Fig. 3 compared with Fig. 2): the ratio of adenosine diphosphate to adenosine triphosphate and glucose-6-phosphate are key variables shared with both short-term studies; fructose diphosphate and dihydroxyacetone phosphate are common to the Climax study; and fructose-6-phosphate is unique to the Leadville polycythemics. These key variables suggest the involvement of the enzymes in the initial part of the glycolytic pathway with 2,3DPG regulation in Leadville polycythemic sample. Of the four kinases implicated by the adenosine diphosphate to adenosine triphosphate ratio, hexokinase and phosphofructokinase are rate-limiting enzymes positioned in the initial part of the pathway. The absence of phosphoenolpyruvate or other intermediates from the latter part of the pathway suggests that the third rate-limiting enzyme, pyruvate kinase, is not involved in the Leadville polycythemic sample.

Hexokinase, phosphofructokinase, and pyruvate kinase normally operate under partial inhibition. Since the mature red blood cell does not synthesize new protein, the maximal activities $\left(V_{\max }\right)$ of the enzymes would not be expected to change at high altitude. An increase in in vivo activities of the enzymes due to release of partial inhibition is the probable mechanism by which the 2,3-DPG build-up occurs. Information on glucose consumption or flux through the pathway is needed, however, to substantiate increased activity. Published 


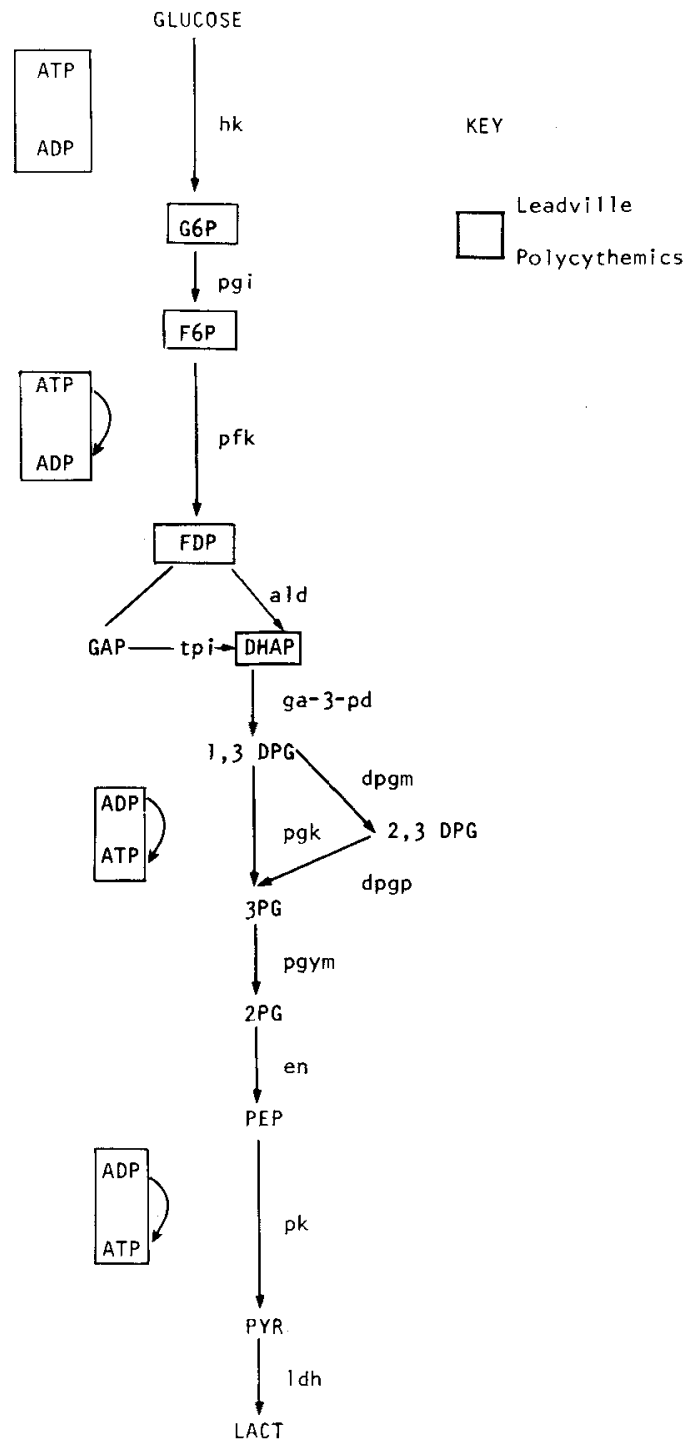

Fig. 3. Key variables (in boxes) in Leadville residents with chronic mountain polycythemia.

data on glucose consumption are not available, and our unpublished observations have shown inconsistent results. A difficulty arises in that available methods measure glucose consumption during an in vitro incubation where the stimuli affecting glycolysis may not be the same as those operating on the red blood cell in vivo. Also, changes in flux in vivo may be below limits of detection (i.e. an increase of $1 \%$ ) yet still be sufficient to result in the observed 2,3DPG changes. Tentatively, we believe that flux increases, at least early in short-term highaltitude exposure, since nearly all the glycoly- tic intermediates increase during the first six hours or two days (Tables 1 and 2). Without an increase in flux, it seems unlikely that intermediates positioned along the length of the glycolytic pathway would all increase. Also, the increase in glucose-6-phosphate levels in both short-term studies and the decrease in the ratio of adenosine diphosphate to adenosine triphosphate at Pike's Peak supports hexokinase activation. The decreased adenosine diphosphate to adenosine triphosphate ratio at Pike's Peak is also consistent with pyruvate kinase activation. Among key variables in the Leadville 
polycythemic sample, lower adenosine diphosphate to adenosine triphosphate ratios and higher dihydroxyacetone phosphate levels support hexokinase and phosphofructokinase activation. Furthermore, the analysis used to identify the key variables supports activation, since the key variable selection was based on the close relationship between variation in the particular intermediate or cofactor with variation in 2,3-DPG levels at each measurement time and under each altitude condition.

Previous methods for interpreting changes in red blood cell metabolism at high altitude or in selected disease states have relied on the crossover plot method of Chance et al. ('58) in which the levels of intermediates after hypoxic stimulus or in patients were plotted as a percent change of their prehypoxic levels or of the levels of a control group (Oelshlegel et al., '72; Moore et al., '72; Rorth et al., '72). The limitations of this approach are (1) that comparisons between a subject's intermediate levels at two times or between two groups of subjects carinot rigorously take account of variation over multiple times or variation within a group of subjects and (2) that comparisons permitted do not lend themselves to hypothesis testing and the determination of statistical significance.

Results of this study differ from those of previous reports on red blood cell metabolic changes responsible for 2,3-DPG build-up at high altitude in which only phosphofructokinase activation was identified (Duhm and Gerlach, '71; Rorth et al., '72). The stimulatory effect of alkalosis on phosphofructokinase has been used previously to support phosphofructokinase as the responsible mechanism. The quantitative approach of the present study also identified phosphofructokinase activation, but only in the Climax short-term study and among high-altitude residents with chronic mountain polycythemia. Roles for pyruvate kinase in the Climax and Pike's Peak short-term studies and for hexokinase in both short-term studies and in the Leadville polycythemics point to the importance of additional portions of the glycolytic pathway in the regulation of 2,3-DPG levels at high altitude. Further research is needed to identify the stimuli operating on these enzymes as well as to determine whether genetic variation exists in glycolytic enzymes among high altitude populations which may lead to differences in enzymatic activities.

\section{ACKNOWLEDGMENTS}

This work received support from the Department of the Army and Navy under contract number DADA 17-69-C-9103, the Wenner Gren Foundation for Anthropological Research grant number 2854, and NIH Training Grant number 5T01-GM-00071-14. Special thanks are due to Dr. Charles F. Sing for advising about the statistical analyses performed. Valuable laboratory assistance was provided by Lucia Brewer and Conrad Knutsen.

Portions of this research were included in Red Blood Cell Adaptation to High Altitude: Mechanisms of the 2,3-DPG Response by L.G. Morre, Ph.D. Thesis, University Microfilms, Ann Arbor (1973).

\section{LITERATURE CITED}

Brewer, G., and R. Powell (1966) The adenosine triphosphate content of G6PD deficient and normal erythrocytes ineluding studies of a G6PD deficient man with elevated erythrocyte ATP. J. Clin. Med., 67:726.

Chance, B., W. Holmes, J. Higgins, C.M. Connelly (1958) Localization of interaction sites in multi-component transfer systems. Nature, 182:1190-1193.

Cymerman, A., J.T. Maher, J.C. Cruz, J.T. Reeves, J.C Denniston, and R.F. Grover (1976) Increased 2.3-diphosphoglycerate during normocapnic hypobaric hypoxia. Aviat. Space. Environ. Med., 47:1069-1072.

Duhm, J., and E. Gerlach (1971) On the mechanisms of the hypoxia-induced increase of 2,3-diphosphoglycerate in erythrocytes. Pflugers Arch., 326:254-269.

Eaton, J., G. Brewer, and R. Grover (1969) Role of red cell 2,3-diphosphoglycerate in the adaptation of man to high altitude. J. Lab. Clin. Med., 73:603-609.

Keitt, A. (1971) Reduced nicotinamide adenine dinucleotide linked analysis of 2,3-DPG. J. Lab. Clin. Med., 470:475.

Kornberg, A. (1950) Reversible enzymatic synthesis of djphosphopyridine nucleotides and inorganic pyrophosphate. J. Biol. Chem., 182:779-793.

Lenfant, C., J. Torrance, E. English, et al. (1968) Effect of altitude on oxygen binding by hemoglobin and on organic phosphate levels. J. Clin. Invest., 47:2652-2656.

Minakami, S., T.C. Suzuki, T. Saito, et al. (1965) Studies on erythrocyte glycolysis. I. Determination of the glycolytic intermediates in human erythrocytes. J. Biochem. (Tokyo), 58:543-550.

Minakami, S., and H. Yoshikawa (1966) Studies on erythrocyte glycolysis. II. Free energy changes and rate limiting steps in erythrocyte glycolysis. J. Biochem. (Tokyo), 59:139-144.

Morre, L.G., G. Brewer, and F. Oelshlegel (1972) Red cell metabolic changes in acute and chronic exposure to high altitude. In Hemoglobin and Red Cell Structure and Function. G. Brewer, ed. New York, Plenum, pp. 397-413.

Oelshlegel, E., G. Brewer, J. Penner, et al. (1972) Enzymatic mechanisms of red cell adaptations to anemia. In Hemoglobin and Red Cell Structure and Function. G. Brewer, ed. New York, Plenum, pp. 372-395.

Rorth, M., S. Nygaard, and H. Parving (1972) Effects of exposure to simulated high altitude on human red cell phosphates and oxygen affinity of hemoglobin. Scand. $J$ Clin. Lab. Invest., 29:329-333. 